\title{
Estimation of dissolved oxygen in riverine ecosystems: Comparison of differently optimized neural networks
}

(i) The corrections made in this section will be reviewed and approved by journal production editor.

Anita Csábrági ${ }^{\mathrm{a}}$ csabragi.anita@gmail.com, Sándor Molnár ${ }^{\mathrm{a}}$ molnar.sandor@gek.szie.hu, Péter Tanos ${ }^{\mathrm{a}}$ tanospeter@gmail.com, József Kovács ${ }^{\mathrm{b}}$

kevesolt@geology.elte.hu, Márk Molnár molnar.mark@gtk.szie.hu, István Szabóa Szabo.Istvan@gek.szie.hu, István Gábor Hatvanid,*

hatvaniiig@gmail.com

aDepartment of Informatics, Szent István University, Páter K. u.1., Gödöllő H-2103, Hungary

bepartment of Physical and Applied Geology, Eötvös Loránd University, Pázmány Péter sétány 1/C., Budapest H-1117, Hungary

`Department of Macroeconomics, Szent István University, Páter K. u.1., Gödöllő H-2103, Hungary

dInstitute for Geological and Geochemical Research, Research Centre for Astronomy and Earth Sciences, MTA Budaörsi út 45, Budapest H-1112, Hungary

*Corresponding author at: Institute for Geological and Geochemical Research, Research Center for Astronomy and Earth Sciences, MTA, Budaörsi út 45.,

Budapest H-1112, Hungary.

\begin{abstract}
Dissolved oxygen is one of the most important water quality parameters in relation to aquatic life, and one of the most direct indicators of water pollution. The present study employs a novel methodology for the estimation of riverine dissolved oxygen using neural network models taking the spatial homogeneity of the water quality sampling sites into account. In three alternative configurations, a multivariate linear regression model, a radial basis function neural network and a general regression neural network are applied to discover which is best able to forecast dissolved oxygen effectively. Data from 13 water quality monitoring stations of the River Tisza are used, including runoff, water temperature, electric conductivity and $\mathrm{pH}$. The three configurations are as follows: (i) a randomly chosen training and test set (which is then considered the reference model), (ii) a training and test set chosen in a spatially controlled way and (iii) a data set composed of two homogeneously behaving sampling sites with the addition of the site lying closest to these downstream. It was found that if the input of the linear model or the neural networks consists of a group or groups of sampling sites displaying homogeneous behavior, better performance is achieved in the estimation. Specifically, the best estimation of dissolved oxygen was achieved in the middle and lower reaches of the river, with an average of $81 \%$ and $87 \%$ of variance explained, respectively; the General Regression Neural Networks gave the best performance, in the middle reaches $\div 85 \%$ and $90 \%$ in the lower ones, respectively, even in the presence of a high degree of anthropogenic activity, as is the case with the River Tisza.
\end{abstract}

Keywords: Combined cluster and discriminant analysis; Dissolved oxygen forecasting; General regression neural networks; Radial basis function neural network; Homogeneous sampling sites

\section{Introduction}

The presence of a sufficient amount of dissolved oxygen (DO) in water is essential for the higher forms of aquatic life to flourish (Connolly et al., 2004; Dodds, 2002). The issues associated with low concentrations of DO in rivers have been recognized for about a century (Thompson, 1925). Low DO content can cause an adverse change in the composition of riverine assemblages (Connolly et al., 2004), as well as fish mortality, odors and other aesthetic nuisances (Cox, 2003). Regular DO dynamics are complex, involving interactions between physical, chemical, and biological processes (Wang et al., 2003). Oxygen can enter the water via two main routes: by direct absorption from the atmosphere, and as a by-product of photosynthesis (Odum, 1956; Schurr and Ruchti, 1977). The amount of DO in an aquatic environment is determined by the various turns in the continuous balancing act between oxygen-producing and oxygen-consuming processes ( Heddam, 2014). Natural waters in equilibrium with the atmosphere typically contain DO concentrations in the range of 5 to $15 \mathrm{mg} \mathrm{L}^{-1} \mathrm{O}_{2}$ depending on water temperature, salinity, and altitude (APHA, 1998). The analysis of this DO content is extremely important in the determination of water quality. Besides its direct measurement, its values are commonly estimated using various deterministic hydrological models (e.g. Soil and Water Assessment Tool, Water Quality Analysis Simulation Program, QUAlity Simulation Along Rivers, Better Assessment Science Integrating Point and Non-point Sources (see Wang et al., 2013)) and statistical models (e.g. Autoregressive integrated moving average model (ARIMA), Analysis of variance). It should be pointed out, however, that these hydrological models are very complex and their application requires a large amount of input information and computational capacity (Kanda et al., 2016; Najah et al., 2011), neither of which may necessarily be available in a given instance (Šiljić Tomić et al., 2016). 
In the case of rivers, DO dynamics may be taken as being in a linear relationship with water temperature, if it is the only driving factor considered. However, in most cases due to the nature of the flow system, and the presence of turbidity, anthropogenic effects, wastewater channeling, etc. the behavior of DO should rather be considered as nonlinear, as it depends on the combination of multiple environmental factors (Chen and Liu, 2014). It should be noted that there are few methodological approaches enat hand to tackle this obstacle. In such circumstances, Artificial Neural Networks (ANNs) may provide a solution. Their use necessitates more sophisticated regression models based on, for instance, Machine Learning (Shaikhina and Khovanova, 2017), which can be utilized by ANNs. Artificial neural networks are flexible modeling tools and are able to approximate accurately complicated non-linear input-output relationships (Palani et al., 2008). This approach has gained widespread acceptance as a potentially useful way of modeling hydrological processes, having been applied to a range of different problems, including water quality, rainfall runoff, sedimentation and rainfall forecasting (Emamgholizadeh et al., 2014, Várbíró et al., 2007).

When neural networks are employed, the data set is broken down into at least two subsets: the training and test sets, and the performance of the various models is influenced fundamentally by the definition of these sets. Three alternatives exist for the division of the sample set into these subsets.

In most cases, an arbitrary division is made when defining the training and test sets. In such cases, the given output is simulated and modeled for the complete system, ignoring the possibility of input optimization (for dissolvention estimation with ANNs in rivers e.g. Antanasijević et al., 2014; Basant et al., 2010; Emamgholizadeh et al., 2014; Heddam, 2014; Kanda et al., 2016; Wen et al., 2013). This division can also be made-done in a non-arbitrary way. For example, the nine sampling points inof the Harsit stream in Turkey were divided in such a manner that all the structures of the data set were included in both the training and test sets (Bayram and Kankal, 2015, Table A1).

In the-literature, there is a smaller number of cases in which the total dataset is divided temporally into several time intervals. The larger dataset is then used as the training set, and the smaller, with the later usually consisting of data from the ultimate period(s)data, for testing. This procedure may be considered a kind of temporal forecasting (see for example: Antanasijević et al., 2013; Ay and Kisi, 2012; Csábrági et al., 2017, 2015; He et al., 2011; Singh et al., 2009; Šiljić Tomić et al., 2016, 2018b).

In an even smaller number of cases, the total dataset is divided into training and test sets according to the sampling locations. For example, on the Melen River, Turkey, of the total of eight sampling points, four were used for training and four for testing (Dogan et al., 2009). Since the assigned sampling points in the sets were not adjacent, but rather sporadically distributed and randomly chosen for incorporation into the model, this procedure cannot be regarded as spatial forecasting, only as modeling or simulation.

One example of temporal forecasting was found, in this case coupled with spatial modeling; this had been undertaken at two sampling locations (upstream, downstream) on the Arkansas River in Colorado (Ay and Kisi, 2012). In every case, the accuracy of the estimation of an ANN model is fundamentally determined by the input, that is, by the structure of the sample set. Multiple sources deal with the optimization of the ANN's sample set, which can be approached from many angles.

The optimization of ANNs can be approached from many angles:

(i) by choosing the most appropriate set of input parameters to maximize the explained variance with the lowest number of parameters (by using e.g. correlation matrices, variance inflation factor, smoothing factors of the individual parameters) (Antanasijević et al., 2014; Ouyang, 2018; Prasad et al., 2017),

(ii) by choosing a set of samples in space which account for most of the variance in the full dataset

(iii) by choosing such time intervals as will again account for most of the variance and in which the data are more homogenous (e.g. by cluster analysis or applying ANNs);

Numer s Studies which show examples for all three optimizations may be found in literature. (e.g. Šiljić Tomić et al., 2016, 2018b.)

The objective of thise presentstudy is to demonstrate the applicability of a novel methodology for estimating dissolved oxygen at water quality sampling sites on the second largest river in Central Europe. In the present instance, this was done by taking into account the spatial homogeneity of groups of sampling sites along a river section to which artificial neural networks were then applied. A key question was whether it is possible to improve spatial forecasting by choosing training and test sets in a directed and conscious manner and by taking into consideration the spatial homogeneity of the river.

\section{Materials and methods}

\subsection{Study area}

The River Tisza_Fig. 1) is the largest tributary of the River Danube, and the second largest river in Hungary. It collects the waters of the northern part of the Carpathian Basin, and as such, it is also an important ecological corridor. It rises in the Ukraine and flows into the Danube at Titel, in the Vojvodina, Serbia. Its watershed is $157,186 \mathrm{~km}^{2}$, and of this, approximately one-third lies in Hungary $\left(47,000 \mathrm{~km}^{2}\right.$ ). Its total length is 966 river km (rkm), across five countries (the Ukraine, Romania, Hungary, Slovakia and Serbia). Its Hungarian tributaries in downstream order of their confluences are: the Szamos, Bodrog, Sajó, Zagyva, Kőrös and Maros.

Not only the tributaries and other inflows, but also artificial installations have a major impact on water quality, e.g. dams/water barrage systems (Kentel and Alp, 2013; Moreira and Poole, 1993); of particular significance is the Tiszalök water barrage system at Tiszalök and its reservoir, the Kisköre Reservoir (a.k.a. Lake Tisza), an artificial lake created in 1973 as part of the hydroelectric power plant, and which became the second largest in Hungary. Nowadays, a popular tourist destination and natural reserve, its length is $27 \mathrm{~km}$, average depth $1.3 \mathrm{~m}$, and total area $127 \mathrm{~km}^{2}$. 
In this particular setting, it has been observed that in the headwater of the hydropower plant planctic algae are more abundant than upstream in the free-flowing river. This is due to the increased residence time (lower flow velocity) of the water, resulting in lower turbidity and much higher transparency (Tanos et al., 2011 ). Therefore, the dam-tailwater will have low dissolved oxygen, not because of the dam itself, but because of the ecological dynamics of the reservoir upstream of the dam (Bevelhimer and Coutant, 2006). This is generally the case in the absence of sustained photosynthetic oxygen production, because the wasteassimilating capacities of headwater ponds are often much lower than those of free-flowing upstream reaches (Butts and Evans, 1978). Efforts have been made to increase dam-tailwater DO release by e.g. turbine venting:_for further examples see ERPI, 2002).

Nonetheless, if the water is nutrient rich but not grossly polluted, excessive algal growth can be expected in the headwater, resulting in supersaturated DO levels (ISWS, 1978; Ruane and Hauser, 1991)

Besides these localized point-sources (e.g. treated sewage outflows, tributaries) the diffuse fertilizer input from the agricultural land, along with the environmental impact of the larger urbanized areas of Szeged and Szolnok also significantly impairs water quality (Kovács et al., 2017; Tanos, 2017).

Bi-weekly measured water quality data was available for the years 1998-2003 from 13 sampling loeations along the Tisza (Fig. 1).

\section{Fig. 1}

Figure Replacement Requested
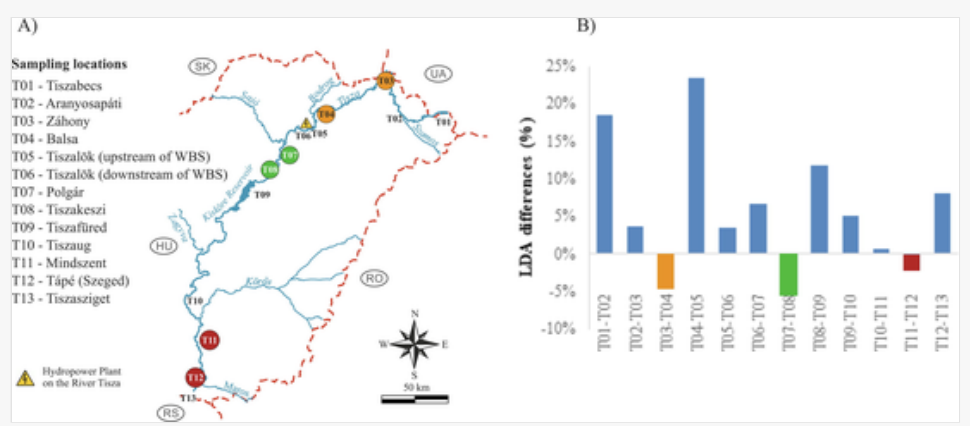

Sampling sites on the Hungarian section of the River Tisza A) and the pairwise differences between neighboring sampling locations calculated using CCDA B). Circles of the same color (A) and the negative values (B) indicate that the given sites form a homogeneous group of sampling sites. LDA in panel (B) stands for linear discriminant analysis.

Replacement Image: Fig1_rev.png

Replacement Instruction: Please replace Fig. 1 with the attached file. Thank you!

\subsection{Water quality data set}

The appropriate selection of input parameters is a decisive step in the process of estimation. For the estimation of dissolved oxygen content (DO), the bi-weekly data of four water quality parameters were used, measured at 13 sampling locations bi-weekly from 1998 to 2003 (Figure 1[Instruction: Please abbreviate Figure to Fig.

]2. The parameter selected as most important was runoff (Q, $\left.\mathrm{m}^{3} \mathrm{sec}^{-1}\right)$, which is fundamental for large rivers (Kovács et al., 2015; Tanos et al., 2015), and which is frequently used in ANN analyses when estimating DO content (Antanasijević et al., 2013; Ay and Kisi, 2012). Temperature ( $\mathrm{T}_{\mathrm{w}}$, ${ }^{\circ} \mathrm{C}$ ) is ${ }^{\text {idely }}$ considered one of the most important parameters in DO content estimation (see; e.g. Bayram and Kankal, 2015; Šiljić Tomić et al., 2018a; Wen et al., 2013). Two further parameters were considered as relevant to DO estimation, $\mathrm{pH}$ and electric conductivity $\left(\mathrm{EC} ; \mu \mathrm{S} \mathrm{cm}^{-1}\right)$. The former was included because its change in a negative direction may reflect communal sewage input (Verma and Singh, 2013) and/or the increased decomposition of organic matter (Akkoyunlu et al. 2011); this, in turn, decreases the DO content. Moreover, from a methodological point of view $\mathrm{pH}$ is frequently used in the estimation of the DO content of lake- and river waters (for details see for example: Bayram and Kankal, 2015; Csábrági et al., 2017; Šiljić Tomić et al., 2018a). On the other hand, conductivity ( $\mu \mathrm{S}$ cm ${ }^{-1}$ ) was chosen since it is a direct indicator of the ion content (dissolved salts) of water (Heddam, 2014; Kanda et al., 2016).

It should also be noted that the set of parameters chosen for the study is one comprising those frequently used for estimating DO content in rivers, as they are quickly and easily measured (Bayram et al., 2015), thus only a very few data are missing from their time series.

\subsection{Steps of analysis and used terminology}

In terms of how the training and test data were chosen in the study, three configurations are presented, all in the proportions of 2:1, the training to test data.

In the first configuration (Tisza configuration 1, TC1 for short, Table A2), the whole dataset (i.e. all sampling locations) pertaining to the River Tisza was considered and subsequently divided in a random way into the training and the test sets. In this case, DO content is modeled over the entire Hungarian section of the river $(594.5 \mathrm{rkm})$. Technically, the random selection of the data was conducted using three different setups, three separate, randomly chosen, but documented seed values. These will be referred to in the study as TC1-A, TC1-B and TC1-C, where the final letters indicate the different setups. Most frequently, the models with the randomly selected data are the reference ones in $\mathrm{NN}$ studies, thus in the present case this first configuration was chosen to serve as the reference for the other two configurations. 
In the second configuration (TC2, Table A2), once again the whole dataset was considered, and four setups were created. In each setup, four neighboring locations were selected as the test set, and the remaining nine locations were used for training. In this way, the desired approx. 2:1 proportion was maintained. In the first setup (TC2-A), the first four sampling sites were considered (T01-T04), then from T04 to T07 (TC2-B), T07-T10 (TC2-C) and finally T10-T13 (TC2D). With the use of this configuration, "spatial forecasting" was attained for DO, as the training and test sets were selected in a controlled manner.

Finally, in the third configuration (TC3, Table A2), the spatial homogeneity of the data was taken into account as an additional factor. Specifically, the previously obtained homogeneous grouping of sampling sites (Tanos et al., 2015) identified using combined cluster and discriminant analysis (CCDA; Kovács et al., 2014) was utilized, and in this configuration, only three subsets of the whole river were considered. It had been previously documented that the 13 sampling locations of the River Tisza can be assigned to 10 homogenous groups (Tanos et al., 2015; Fig. 1). Three of the groups contain two sampling locations, one each in the upper- middle- and lower reaches (Fig. 1B). CCDA was then employed to group samples or, in the present ease, sampling loeations; this grouping involved not simply assigning them to similar/optimal groups or subsets, but homogeneous ones (Kováes et al., 2014, 2015). [Instruction: please add an enter here, so "In realtion to this,..." would start in a new paragraph. Thank you!

JIn relation to this, the key point of CCDA is that it compares all combinations of hierarchical cluster groups to random groupings and suggests the further division of the obtained cluster groups using a difference value obtained from linear discriminant analysis (Kovács et al., 2014). If this difference value is negative, the grouping obtained is homogeneous, and if not, then further division is required (Kovács et al., 2014).

Since the size of the homogeneous groups of sampling sites was-amaximum of two sites in the multisite groups, a third location had to be considered, aside from the two composing the homogeneous groups, in the ANN runs. In the present instance, this was always the neighboring downstream sampling location. In the first setup of Configuration 3, the first homogeneous group of sampling sites and the neighboring downstream site were considered (TC3-A), then the second homogeneous group, plus one site (TC3-B), followed by the third (TC3-C); in all setups, nine sub-setups were examined, on the basis of two sites providing the training, and one the test data. Therefore, in the third configuration, nine sub-setups were investigated, ranging from TC3-A\#1 to TC3-C\#3.

In the different setups, two kinds of neural networks were employed for estimation: Radial Basis Function Neural Networks (RBFNN; see the details in Supplementary Online Material (SOM)), and General Regression Neural Networks (GRNN; see in SOM). Additionally, a multivariate linear regression (MLR, Draper and Smith, 1981, Reddy, 2011) model was used. This latter was used as a reference to compare the performance of the different ANNs with (Ji et al., 2017), as in numerous other studies (e.g. Antanasijević et al., 2013; Ay and Kisi, 2012; Bayram and Kankal, 2015; Heddam, 2014; Ji et al., 2017); the aim was to ensure the replicability of the applied methodology.

Data were preprocessed: (i) as the necessary first step in any modeling procedure outlying and extreme values (Fig. A2) were removed from all the used datasets (Ben-Gal, 2010) following a robust univariate approach introduced by Mosteller \& Tukey (1977). The boxplot approach is based on the distribution quadrants ( Ben-Gal, 2010), and is frequently used in ANN studies, such as the one estimating dissolved oxygen in the Danube (Šiljić Tomić et al., 2018a), and (ii) values were standardized before their use as ANN input. Model performance was characterized by metrics: root mean square error (RMSE) and the Pearson coefficient of determination $\left(\mathrm{R}^{2}\right)$ (Legates and McCabe, 1999).

To give a little more detail, the different setups/sub-setups, methodological approaches and an additional geographical factor were considered and compared to obtain an overview of which section of the river and which model and data structure would provide the most reliable estimation.

The neural networks were implemented in MATLAB (Neural Network Toolbox, Demuth and Beale, 2000), MS-_Excel Data Analysis ToolPak was used for MLR analyses, the contour maps were drawn using Golden Software SURFER urfer, and CCDA (Kovács et al., 2014) was applied using R 3.5.0 (R Core Team, 2018).

\section{Results}

\subsection{Overview of the data}

The descriptive statistics of the 13 sampling locations on the River Tisza were examined for the years 1998 to 2003 to obtain an overall picture of the water quality characteristics of the various river sections (Table 1, Fig. A2). It was observed that the average runoff of the river quadruples from Tiszabecs (entry point of the river into the country) to Tiszasziget (the last sampling site in Hungary), while it has also been observed that the flow velocity decreases parallel to this ( Hatvani et al., 2018; EC, 2015). Heading downstream, the pH of the river can be considered quasi constant, while EC increased by $50 \%$ (Table 1).

Table 1

(i) The presentation of Tables and the formatting of text in the online proof do not match the final output, though the data is the same. To preview the actual presentation, view the Proof.

Descriptive statistics of the 13 sampling locations on the River Tisza after data filtering (CV: coefficient of variation; n: number of samples). US-WBS and DS-WBS stand for the sampling sites upstream and downstream of the Tiszalök water barrage system, respectively.

\begin{tabular}{|c|c|c|c|c|c|c|c|c|}
\hline Sampling sitelocation name & Sampling sitelocation code & $\mathbf{n}$ & Statistic & $Q\left(m^{3}\right.$ sec $\left.-{ }^{1}\right)$ & $\mathbf{T}_{\mathbf{w}}\left({ }^{\circ} \mathrm{C}\right)$ & pH & $\mathrm{EC}\left(\mathrm{uS} \mathrm{cm}^{-1}\right)$ & DO $\left(\mathrm{mg} \mathrm{l}^{-1}\right)$ \\
\hline \multirow[t]{3}{*}{ Tiszabecs } & \multirow[t]{3}{*}{$\mathrm{T} 1$} & \multirow[t]{3}{*}{128} & $\min$ & 42.3 & 0.0 & 7.40 & 169.0 & 5.91 \\
\hline & & & $\max$ & 448.0 & 26.5 & 8.12 & 440.0 & 22.10 \\
\hline & & & mean & 159.9 & 10.8 & 7.79 & 291.0 & 13.96 \\
\hline
\end{tabular}




\begin{tabular}{|c|c|c|c|c|c|c|c|c|}
\hline & & & $\mathrm{CV}$ & $60 \%$ & $80 \underline{76} \%$ & $2 \%$ & $20 \%$ & $20 \%$ \\
\hline \multirow{4}{*}{ Aranyosapáti } & \multirow{4}{*}{ T2 } & \multirow{4}{*}{116} & $\min$ & 56.1 & 0.0 & 7.36 & 188.0 & 6.64 \\
\hline & & & $\max$ & 685.0 & 26.1 & 8.14 & 590.0 & 18.35 \\
\hline & & & mean & 253.0 & 11.6 & 7.77 & 363.3 & 12.77 \\
\hline & & & $\mathrm{CV}$ & $55 \%$ & $7 \underline{0} \theta \%$ & $2 \%$ & $25 \%$ & $20 \%$ \\
\hline \multirow{4}{*}{ Záhony } & \multirow{4}{*}{$\mathrm{T} 3$} & \multirow{4}{*}{122} & $\min$ & 74.0 & 0.0 & 7.30 & 219.0 & 8.20 \\
\hline & & & $\max$ & 738.0 & 26.4 & 8.19 & 650.0 & 19.00 \\
\hline & & & mean & 304.1 & 11.5 & 7.76 & 403.3 & 12.89 \\
\hline & & & $\mathrm{CV}$ & $51 \%$ & $7 \theta \underline{3} \%$ & $2 \%$ & $22 \%$ & $19 \%$ \\
\hline \multirow{4}{*}{ Balsa } & \multirow{4}{*}{$\mathrm{T} 4$} & \multirow{4}{*}{113} & $\min$ & 52.6 & 0.0 & 7.45 & 256.0 & 6.43 \\
\hline & & & $\max$ & 738.0 & 27.0 & 8.18 & 609.0 & 19.20 \\
\hline & & & mean & 300.0 & 11.5 & 7.79 & 407.4 & 13.07 \\
\hline & & & $\mathrm{CV}$ & $52 \%$ & $7 \theta \underline{3} \%$ & $2 \%$ & $17 \%$ & $20 \%$ \\
\hline \multirow{4}{*}{ US-WBS } & \multirow{4}{*}{ T5 } & \multirow{4}{*}{133} & $\min$ & 73.0 & 0.0 & 7.31 & 217.0 & 3.60 \\
\hline & & & $\max$ & 1293.2 & 28.0 & 8.15 & 502.0 & 12.80 \\
\hline & & & mean & 369.4 & 12.5 & 7.73 & 369.7 & 9.43 \\
\hline & & & $\mathrm{CV}$ & $73 \%$ & $70 \underline{73} \%$ & $2 \%$ & $20 \%$ & $23 \%$ \\
\hline \multirow{4}{*}{ DS-WBS } & \multirow{4}{*}{ T6 } & \multirow{4}{*}{128} & $\min$ & 10.0 & 0.0 & 7.47 & 202.0 & 4.20 \\
\hline & & & $\max$ & 1152.0 & 27.1 & 8.31 & 520.0 & 13.60 \\
\hline & & & mean & 354.4 & 12.8 & 7.83 & 360.6 & 9.68 \\
\hline & & & $\mathrm{CV}$ & $65 \%$ & $70 \underline{69} \%$ & $2 \%$ & $20 \%$ & $23 \%$ \\
\hline \multirow{4}{*}{ Polgár } & \multirow{4}{*}{$\mathrm{T} 7$} & \multirow{4}{*}{128} & $\min$ & 62.0 & 0.1 & 7.53 & 227.0 & 4.70 \\
\hline & & & $\max$ & 1385.0 & 27.0 & 8.19 & 554.0 & 13.20 \\
\hline & & & mean & 458.3 & 13.2 & 7.84 & 389.7 & 9.75 \\
\hline & & & $\mathrm{CV}$ & $61 \%$ & $70 \underline{66} \%$ & $2 \%$ & $19 \%$ & $21 \%$ \\
\hline \multirow{4}{*}{ Tiszakeszi } & \multirow{4}{*}{ T8 } & \multirow{4}{*}{131} & $\min$ & 62.0 & 0.2 & 7.54 & 230.0 & 5.40 \\
\hline & & & $\max$ & 1385.0 & 27.3 & 8.29 & 538.0 & 13.10 \\
\hline & & & mean & 454.5 & 13.6 & 7.87 & 382.8 & 9.77 \\
\hline & & & $\mathrm{CV}$ & $61 \%$ & $6 \theta \underline{4} \%$ & $2 \%$ & $20 \%$ & $22 \%$ \\
\hline \multirow{4}{*}{ Tiszafüred } & \multirow{4}{*}{ T9 } & & $\min$ & 54.0 & 0.0 & 7.55 & 227.0 & 4.30 \\
\hline & & & $\max$ & 1530.0 & 27.2 & 8.40 & 550.0 & 13.70 \\
\hline & & & mean & 478.7 & 12.8 & 7.96 & 380.1 & 9.68 \\
\hline & & & $\mathrm{CV}$ & $73 \%$ & $70 \%$ & $2 \%$ & $21 \%$ & $23 \%$ \\
\hline & & & $\min$ & 70.6 & 0.0 & 7.65 & 227.0 & 5.40 \\
\hline & & & $\max$ & 1420.0 & 27.6 & 8.30 & 600.0 & 13.50 \\
\hline & & & mean & 488.7 & 12.9 & 7.99 & 405.1 & 9.48 \\
\hline & & & $\mathrm{CV}$ & $69 \%$ & $70 \underline{69} \%$ & $2 \%$ & $20 \%$ & $24 \%$ \\
\hline & & & $\min$ & 65.2 & 0.2 & 7.71 & 215.0 & 5.00 \\
\hline & & & $\max$ & 1939.0 & 28.4 & 8.25 & 620.0 & 12.90 \\
\hline & & & mean & 686.1 & 13.6 & 7.99 & 385.8 & 9.12 \\
\hline & & & $\mathrm{CV}$ & $70 \%$ & $60 \%$ & $1 \%$ & $22 \%$ & $23 \%$ \\
\hline Tápé & $\mathrm{T} 12$ & 133 & $\min$ & 65.0 & 0.0 & 7.51 & 235.0 & 4.50 \\
\hline & & & $\max$ & 1939.0 & 29.1 & 8.33 & 645.0 & 12.90 \\
\hline & & & mean & 707.4 & 13.2 & 7.92 & 386.4 & 9.04 \\
\hline
\end{tabular}




\begin{tabular}{|c|c|c|c|c|c|c|c|c|}
\hline & & & $\mathrm{CV}$ & $69 \%$ & $6 \theta \underline{3} \%$ & $2 \%$ & $22 \%$ & $24 \%$ \\
\hline \multirow{4}{*}{ Tiszasziget } & \multirow{4}{*}{$\mathrm{T} 13$} & \multirow{4}{*}{136} & $\min$ & 101.0 & 0.0 & 7.61 & 243.0 & 4.80 \\
\hline & & & $\max$ & 2180.0 & 28.4 & 8.33 & 660.0 & 13.20 \\
\hline & & & mean & 831.3 & 13.1 & 7.98 & 425.1 & 9.32 \\
\hline & & & $\mathrm{CV}$ & $62 \%$ & $70 \underline{65} \%$ & $2 \%$ & $22 \%$ & $22 \%$ \\
\hline
\end{tabular}

The monthly average values for dissolved oxygen decreased towards the lower reaches by $\sim 30 \%$ compared to those measured in the upper sections (Fig. $2 \mathrm{a} \underline{\mathrm{A}}$ ), while temperature increased significantly, by $\sim 3^{\circ} \mathrm{C}$ (Fig. 2 b $\underline{B}$ ).

\section{Fig. 2}

Figure Replacement Requested

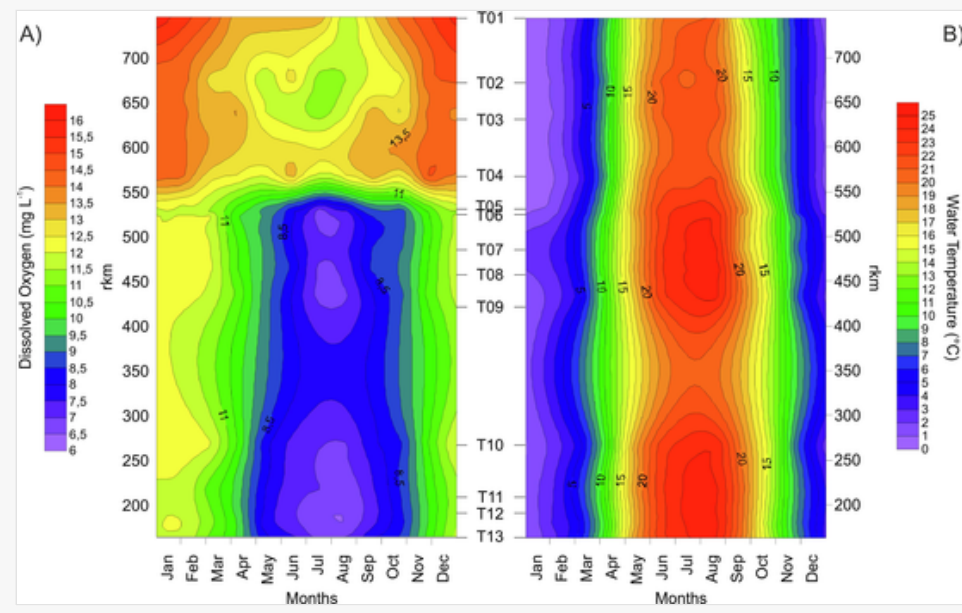

Monthly averages of DO concentration A) and temperature B) observed in the River Tisza (1998-2003). The codes of the sampling locations are given between the two panels

Replacement Image: Fig.2_rev.png

Replacement Instruction: Please replace the figure with the attached Fig. 2 rev. Thank you!

It may be easily observed that the first four sampling locations, from Tiszabecs to Balsa (T01, T02, T03 and T04), show higher DO values than the sites located downstream from the WBS, which slows the water of the River Tisza down (Tanos (2017; Fig. 2a $\underline{A}$ ). This is therefore suspected to be a result of the decreased flow velocity of the river (Hatvani et al., 2018); this has also been seen in other rivers (Cox, 2003).

\subsection{The first configuration - Baseline model}

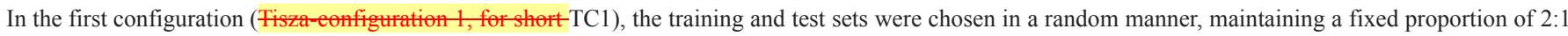
to obtain the three setups TC1-A, TC1-B and TC1-C (for details, please see Sect. 2.3).

The RBFNN and RGNN models were compared to the fitted MLR models (Table 2). The MLR was first applied to the training set and its significance assessed (F-values), then the p-values of the independent variables were calculated. If in any case the p-value $>0.05$, then the variable was omitted and the model was reapplied. The analysis reached its end when all independent variables showed a level of significance; $p<0.05$. The intercept and the coefficients of the independent variables were determined and used in an estimation conducted on the test set, and the various metrics were determined for the evaluation of the goodness of fit of the estimation. The variables used in the model runs are listed for each MLR result, and the same logic is followed for the remaining applications of the MLR.

Table 2

(i) The presentation of Tables and the formatting of text in the online proof do not match the final output, though the data is the same. To preview the actual presentation, view the Proof.

Results of the three random selections for the test set for all three models (Configurations TC1-A to TC1-C): the attributes column shows the variables used in the MLR model,- the smoothing factor applied in the GRNN and RBFNN models, and the neuron count of the hidden layer (in brackets) for the latter ANN model.

$\begin{array}{llll}\text { Setups } & \text { Modell } & \text { RMSE }\left(\mathrm{mg} \mathrm{L}^{-1}\right) & \mathbf{R}^{2}\end{array}$




\begin{tabular}{|l|l|l|l|}
\hline MLR & 2.18 & 0.44 & Q, Tw, EC \\
\hline GRNN & 2.10 & 0.48 & 0.34 \\
\hline RBFNN & 2.12 & 0.47 & $0.37(84)$ \\
\hline MLR & 1.96 & 0.53 & Q, Tw, EC \\
\hline GRNN & 1.88 & 0.57 & 0.4 \\
\hline RBFNN & 1.91 & 0.55 & $0.46(32)$ \\
\hline MLR & 2.14 & 0.43 & Q, Tw, EC \\
\hline GRNN & 2.03 & 0.48 & 0.42 \\
\hline RBFNN & 2.11 & 0.45 & $0.4(51)$ \\
\hline
\end{tabular}

Results highlighted the fact that in all three setups of the first configuration, the ANNs gave a better estimation than MLR, which had the highest RMSE and a lower value of $\mathrm{R}^{2}$ in all cases (Table 2). The best result was obtained in the TC1-B setup with the GRNN model $\left(\mathrm{RMSE}=1.88 \mathrm{mgL}^{-1} ; \mathrm{R}^{2}=0.57\right)$; this was subsequently used as a reference when assessing other results, and its RMSE value was taken as a reference. The goal was to improve this reference value in the following two configurations (TC2 and TC3).

\subsection{The second configuration - Controlled selection}

In the second configuration (TC2), again, the complete dataset was used in the analysis. Nine sampling locations were used for training and four neighboring locations for testing in each run in order to be able to create distinctive models of different sections of the river.

Of the four setups, that whe the overall best performance was obtained-mg $\mathrm{E}$ in the case of the TC2-C setup. Taking all four setups together, the difference between the MLR model and the ANNs was just marginal, while MLR outperformed the ANNs with respect to RMSE, but not in the case of $\mathrm{R}^{2}-\underline{\text { Table }} 3 \stackrel{2}{-}$

Table 3

(i) The presentation of Tables and the formatting of text in the online proof do not match the final output, though the data is the same. To preview the actual presentation, view the Proof.

Results of the four setups, with a proportion of 9 training to 4 test sets. For a description of the attribute column, please see the caption of Table 2. also have the same

\begin{tabular}{|c|c|c|c|c|}
\hline Setups & Modell & RMSE (mg L $\left.{ }^{-1}\right)$ & $\mathrm{R}^{2}$ & Attributes \\
\hline \multirow{3}{*}{ TC2-A } & MLR & 4.25 & 0.11 & $\mathrm{Q}, \mathrm{T}_{\mathrm{w}}, \mathrm{pH}, \mathrm{EC}$ \\
\hline & GRNN & 4.32 & 0.09 & 1.28 \\
\hline & RBFNN & 4.33 & 0.14 & $0.11(198)$ \\
\hline \multirow{3}{*}{ TC2-B } & MLR & 2.44 & 0.29 & $\mathrm{Q}, \mathrm{T}_{\mathrm{w}}, \mathrm{pH}, \mathrm{EC}$ \\
\hline & GRNN & 2.46 & 0.27 & 0.32 \\
\hline & RBFNN & 2.47 & 0.27 & $0.31(85)$ \\
\hline \multirow{3}{*}{ TC2-C } & MLR & 1.53 & 0.71 & $\mathrm{Q}, \mathrm{T}_{\mathrm{W}}, \mathrm{EC}$ \\
\hline & GRNN & 1.60 & 0.64 & 0.46 \\
\hline & RBFNN & 1.63 & 0.58 & $0.43(70)$ \\
\hline \multirow{3}{*}{ TC2-D } & MLR & 1.55 & 0.57 & $\mathrm{Q}, \mathrm{T}_{\mathrm{w}}, \mathrm{EC}$ \\
\hline & GRNN & 1.67 & 0.67 & 0.46 \\
\hline & RBFNN & 1.80 & 0.51 & $0.41(127)$ \\
\hline
\end{tabular}

\subsection{Third configuration, taking the spatial homogeneity of the sampling sites into account}

In the third configuration (TC3), groups of homogeneous sampling sites and their neighboring downstream site were considered.

To identify locations. The first assessment targeted neighboring sampling locations. Subsequently, all possible pairs of sampling points were compared (Table 4). These 
pairwise comparisons confirmed the earlier CCDA result, which showed that pairs T03-T04, T07-T08 and T11-T12, respectively, form homogenous groups (Fig. 1, Table 4).

\section{Table 4}

(i) The presentation of Tables and the formatting of text in the online proof do not match the final output, though the data is the same. To preview the actual presentation, view the Proof.

Differences between sampling sites calculated by CCDA.

\begin{tabular}{|c|c|c|c|c|c|c|c|c|c|c|c|c|c|}
\hline ECDASampling location & T01 & T02 & T03 & T04 & T05 & T06 & T07 & T08 & T09 & T10 & T11 & T12 & $\mathbf{T 1 3}$ \\
\hline \multicolumn{14}{|l|}{$\mathrm{TO4}$} \\
\hline T02 & 0.19 & & & & & & & & & & & & \\
\hline T03 & 0.27 & 0.04 & & & & & & & & & & & \\
\hline T04 & 0.30 & 0.06 & -0.05 & & & & & & & & & & \\
\hline T05 & 0.33 & 0.25 & 0.24 & 0.23 & & & & & & & & & \\
\hline T06 & 0.31 & 0.23 & 0.21 & 0.25 & 0.04 & & & & & & & & \\
\hline T07 & 0.34 & 0.23 & 0.23 & 0.23 & 0.10 & 0.07 & & & & & & & \\
\hline T08 & 0.33 & 0.23 & 0.22 & 0.21 & 0.10 & 0.05 & -0.06 & & & & & & \\
\hline T09 & 0.35 & 0.29 & 0.27 & 0.25 & 0.22 & 0.11 & 0.11 & 0.12 & & & & & \\
\hline $\mathrm{T} 10$ & 0.38 & 0.33 & 0.28 & 0.28 & 0.27 & 0.17 & 0.17 & 0.19 & 0.05 & & & & \\
\hline T11 & 0.40 & 0.34 & 0.31 & 0.33 & 0.31 & 0.20 & 0.18 & 0.19 & 0.03 & 0.01 & & & \\
\hline $\mathrm{T} 12$ & 0.37 & 0.30 & 0.25 & 0.25 & 0.20 & 0.10 & 0.12 & 0.09 & 0.06 & 0.05 & -0.02 & & \\
\hline $\mathrm{T} 13$ & 0.40 & 0.33 & 0.31 & 0.29 & 0.30 & 0.24 & 0.18 & 0.19 & 0.16 & 0.13 & 0.10 & 0.08 & \\
\hline
\end{tabular}

In terms of all three setups, it was always the third sub-setup which gave the best results (TC3-A\#3, TC3-B\#3 and TC3-C\#3), and always the GRNN model which provided the most efficient estimation (Table 5). In setup TC3-B, the second and third sub-setups (TC3-B\#2 and TC3-B\#3) yielded almost the same RMSE values using GRNN, but the RMSE turned out to be slightly smaller in the third sub-setup.

\section{Table 5}

(i) The presentation of Tables and the formatting of text in the online proof do not match the final output, though the data is the same. To preview the actual presentation, view the Proof.

Results of analyses conducted on the extended homogeneous groups of sampling sites and using all sub-setups. For a description of the attribute column please see the caption to Table 2.

\begin{tabular}{|c|c|c|c|c|c|}
\hline Sub-setups & Training stations [] \& test station & Model & RMSE $\left(\mathrm{mg} \mathrm{L}^{-1}\right)$ & $\mathbf{R}^{2}$ & Attributes \\
\hline \multirow{3}{*}{ TC3-A\#1 } & \multirow{3}{*}[\mathrm{T}03:-\mathrm{T}04]{$\& \mathrm{~T} 05$} & MLR & 3.64 & 0.68 & $\mathrm{~T}_{\mathrm{w}}, \mathrm{pH}$ \\
\hline & & GRNN & 3.85 & 0.52 & 1.12 \\
\hline & & RBFNN & 3.90 & 0.28 & $0.3(77)$ \\
\hline \multirow{3}{*}{ TC3-A\#2 } & \multirow{3}{*}[\mathrm{T}03-\dot{2}\mathrm{T}05]{$\& \mathrm{~T} 04$} & MLR & 3.12 & 0.06 & $\mathrm{~T}_{\mathrm{w}}, \mathrm{pH}, \mathrm{EC}$ \\
\hline & & GRNN & 2.69 & 0.25 & 0.32 \\
\hline & & RBFNN & 2.82 & 0.27 & $0.34(59)$ \\
\hline \multirow{3}{*}{ TC3-A\#3 } & \multirow{3}{*}[\mathrm{T}04-;\mathrm{T}05]{$\& \mathrm{~T} 03$} & MLR & 2.86 & 0.14 & $\mathrm{~T}_{\mathrm{w}}, \mathrm{pH}, \mathrm{EC}$ \\
\hline & & GRNN & 2.47 & 0.28 & 0.48 \\
\hline & & RBFNN & 2.33 & 0.31 & $0.4(47)$ \\
\hline \multirow{3}{*}{ TC3-B\#1 } & \multirow{3}{*}[\mathrm{T}07-;\mathrm{T}08]{$\& \mathrm{~T} 09$} & MLR & 1.18 & 0.79 & $\mathrm{~T}_{\mathrm{w}}, \mathrm{pH}, \mathrm{EC}$ \\
\hline & & GRNN & 1.19 & 0.78 & 0.54 \\
\hline & & RBFNN & 1.25 & 0.76 & $0.13(29)$ \\
\hline
\end{tabular}




\begin{tabular}{|c|c|c|c|c|c|}
\hline \multirow[t]{3}{*}{ TC3-B\#2 } & \multirow[t]{3}{*}{ [T07-: T09] \& T08 } & MLR & 0.94 & 0.82 & $\mathrm{~T}_{\mathrm{w}}, \mathrm{pH}$ \\
\hline & & GRNN & 0.84 & 0.85 & 0.42 \\
\hline & & RBFNN & 0.88 & 0.84 & $0.15(31)$ \\
\hline \multirow{3}{*}{ TC3-B\#3 } & \multirow{3}{*}{ [T08-: T09] \& T07 } & MLR & 0.98 & 0.79 & $\mathrm{~T}_{\mathrm{w}}, \mathrm{pH}$ \\
\hline & & GRNN & 0.83 & 0.85 & 0.4 \\
\hline & & RBFNN & 0.91 & 0.82 & $0.15(29)$ \\
\hline \multirow{3}{*}{ TC3-C\#1 } & \multirow{3}{*}[T11-:\mathrm{T}12]{$\& \mathrm{~T} 13$} & MLR & 0.82 & 0.87 & $\mathrm{Q}, \mathrm{T}_{\mathrm{w}}, \mathrm{pH}, \mathrm{EC}$ \\
\hline & & GRNN & 0.73 & 0.88 & 0.6 \\
\hline & & RBFNN & 0.80 & 0.87 & $0.15(36)$ \\
\hline \multirow{3}{*}{ TC3-C\#2 } & \multirow{3}{*}[\mathrm{T}11-;\mathrm{T}13]{$\& \mathrm{~T} 12$} & MLR & 0.81 & 0.87 & $\mathrm{Q}, \mathrm{T}_{\mathrm{w}}, \mathrm{pH}, \mathrm{EC}$ \\
\hline & & GRNN & 0.73 & 0.90 & 0.54 \\
\hline & & RBFNN & 0.84 & 0.86 & $0.06(68)$ \\
\hline \multirow{3}{*}{ TC3-C\#3 } & \multirow{3}{*}[\mathrm{T}12-;\mathrm{T}13]{$\& \mathrm{~T} 11$} & MLR & 0.76 & 0.87 & $\mathrm{Q}, \mathrm{T}_{\mathrm{w}}, \mathrm{pH}, \mathrm{EC}$ \\
\hline & & GRNN & 0.77 & 0.87 & 0.58 \\
\hline & & RBFNN & 0.76 & 0.87 & $0.08(32)$ \\
\hline
\end{tabular}

Comparing the different sub-setups of the third configuration, the efficiency of the ANNs in the upper and middle reaches improved if the training set included one location from the homogenous group and one external location compared to those where elements of the homogenous groups were used as training sets and the neighboring (nonhomogeneous) sampling locations for the test set (Table 5: TC3-A\#1 and, TC3-B\#1). These sub-setups are from this point on called 'mixed structures'. However, this improvement weakens as the similarity of the sampling sites increases heading downstream (Table 4), to a point where in sub-setup TC3-C no significant difference can be seen between the mixed and non-mixed structures.

\section{Discussion}

\subsection{The effectiveness of DO estimation without taking the spatial homogeneity of water quality sampling sites into account}

In the reference model (TC1-B) there was an a priori assumption that the whole section of the river may be considered as one water body, i.e. it is expected that a single model would be capable of describing adequately an almost $600 \mathrm{rkm}$ long section. In other words, the model derived to estimate DO has to provide an acceptable result regardless of the spatial location of the estimation. This approach is generally employed, as in a study in which biological oxygen demand and DO were estimated using eight sampling locations over a $500 \mathrm{rkm}$ section of the River Gomti (India), applying random distribution in the formulation of the training and test sets (Basant et al., 2010). Another study then attempted to provide a temporal forecast for the whole river section (Singh et al., 2009). In the case of both studies, the application of a MLPNN was successful (RMSE: $1.36 \mathrm{mgL}^{-1}$ (Basant et al., 2010) and $1.23 \mathrm{mgL}^{-1}$ (Singh et al., 2009) for the test set, also, Table A1). MLPNN with the Bayesian regularization training algorithm was used on the Heihe River (China) to estimate DO based on water quality data covering six years from three sampling sites. The sampling sites were randomly chosen to be training and test sets, and exceptional results were achieved for this type of approach (Wen et al., 2013, RMSE: $0.46 \mathrm{mg} \mathrm{L}^{-1}$, Table A1). Over a $143 \mathrm{rkm}$ section of the Turkish Harsit Stream, DO concentration was estimated using $\mathrm{T}$ and $\mathrm{pH}$ data from nine sampling points by splitting the dataset seasonally and choosing the training and test sets randomly within the various seasons using MLR and MLPNN models. Again, MLPNN gave the best performance (RMSE $0.09 \mathrm{mgL}^{-1}$ difference from the test set (Bayram and Kankal, 2015)). In Iran, data from eight sampling stations on the River Karoon were used to estimate DO concentration, also based on a random allocation into training and data sets ( Emamgholizadeh et al., 2014). Three models were applied: adaptive neuro-fuzzy inference system, MLPNN and RBFNN, using nine input parameters and an RMSE of $3.15 \mathrm{mg} \mathrm{L}^{-1}$ was obtained (Table A1). In the highly contaminated and hypoxic Wen-Rui Tang River (China), DO concentration was estimated at eight sampling sites using MLR, GRNN, MLPNN and a support vector machine model; of these locations, it was the latter that provided the best result (RMSE $=0.97 \mathrm{mg} \mathrm{L}^{-1}$; Ji et al., 2017, Table A1).

In the Serbian section of the River Danube (588 rkm) DO concentration was estimated from a single set of sites with random allocation using 10 input parameters and a GRNN model with a figure for the RMSE of $\sim 0.85 \mathrm{mgL}^{-1}$ (Antanasijević et al., 2014). This result was only slightly below the best performance documented in the present study (TC3-C\#2: $0.73 \mathrm{mg} \mathrm{L}^{-1}$, Table A1).

The main assumption of the reference model (TC1-B) - and the studies above - that a given river section can be described by one single model cannot be met when the particular section is hundreds of kilometres long. This finding is underlined by the changes in DO concentration observed along the examined river section (Fig. 2a $\underline{A}$ ), which show that the first $150 \mathrm{rkm}$ section is characterized by a higher DO concentration than the subsequent section. This suggested the idea that in the course of extended systems, such an ANN model should be used which takes into account whether different sub-sections of a river behave in characteristically different ways or homogeneously in terms of water quality. This kind of approach is, however, only rarely encountered. In one case, the uppermost sampling station of the Arkansas River was used to estimate the DO content of a downstream one (Ay and Kisi, 2012), as in the present study, using the exact same set of parameters. Two ANN models were compared to an MLR one, and the former models yielded the best result $\left(\mathrm{RMSE}=0.66 \mathrm{mg} \mathrm{L}^{-1}\right)$, which 
was much lower than (i) any of the previously mentioned models, i.e. those which did not differentiate any sub-sections in the river, or (ii) in the first configurations of the present study (TC1; Table 2).

Properly considered, the spatial characteristics of the examined hydrological systems may be exploited to direct the selection of sampling points for test and training sets. In the second configuration (Sects. 3.3 and 4.2), therefore, separate estimations were made for the respective sections of the river, making it a spatial forecasting approach.

\subsection{The importance of taking into account the spatial distribution of the sampling sites}

It is generally known that lengthy sections of large rivers may not share the same qualities as documented on the Austrian and Hungarian sections of the River Danube by CCDA (Chapman et al., 2016; Kovács et al., 2015). This notion was also incorporated into the model applied to the Serbian section of the Danube for temporal biological oxygen demand forecast. There the 17 Danubian stations were divided into two groups with the aid of the GRNN model (Šiljić Tomić, et al., 2016). Temporal forecasts were also made for DO content in which the Box-Behnken method was used for the allocation of sampling points into the respective subsets (from Bezdan to Zemun, and from Pančevo to Radujevac, Šiljić Tomić, et al. (2018b), Table A1). This conjecture also held true for the Hungarian section of River Tisza, as confirmed both by the second configuration and CCDA (see Sect. 3.4).

In the second configuration (TC2), DO concentration variability was examined using a selection of sampling points for training and test sets as described in Sect. 2.3. In this case, four separate setups were created to describe the Hungarian section of the river. Two (TC2-C and TC2-D) gave more precise, estimations for the lower and middle sections of the river compared to the reference model (TC1-B, Fig. A1).

For the upper section however, the models of configuration 2 (TC2-A and TC2-B), performed worse than the reference model (TC1-B). This is most probably due to the larger variability of water quality in the upper reaches of a river (Reynolds, 1984; Stanković et al., 2012; Bolgovics et al., 2017), as was also seen in the case of the River Tisza (Table 2), making the estimation more difficult (Fig. 2B). This, from a technical point of view, manifested itself in the fact that ANNs are unable to extrapolate beyond the range of the data used for training, and therefore poor forecasts/predictions are only to be expected when the test data contain values outside of the range of those used for training (Maier and Dandy, 2000).

The greater degree of variability in the upper reaches, where TC2-A and TC2-B performed worse than the models of the lower reaches (TC2-C and TC2-D), was also reflected in the pairwise differences indicated by CCDA (Table 4, Fig. 1B). In the upper reaches, the average difference between the sampling sites selected for the test set was higher than the difference between the sampling sites in the test set in TC2C-D ( $+9 \%$; Table 4, Fig. 1B). A further problem was caused by the fact that in the case of the second setup the four sampling locations in the respective configurations (from TC2-A to TC2-C) precede the sampling locations of the training set, therefore compelling the estimation of the upper sections to be conducted using data and characteristics from the lower sections. This effect is emphasized in the result of TC2-A.

This finding is in accord with the fact that in general the variance of water quality parameters is reduced downstream, with the degree depending on the season and the stream itself (Abonyi et al., 2012; Kovács et al., 2017; Tanos et al., 2015). It therefore comes as no surprise that the same phenomena occurred in the case of the River Tisza, also. The concept of the second configuration - to provide separate estimations for different river sections - proved to be justified, since the results obtained from the reference model were improved, as may be seen in the two setups TC2-C and TC2-D.

\subsubsection{Incorporation of spatial homogeneity of the river section's sampling sites in the ANN model estimating DO, determined by CCDA}

In order to improve the efficiency of the forecast, the results of CCDA (Figure 1.Fable 4)[Instruction: Please abbreviate to 'Fig. 1'

] were incorporated (in the form of homogeneous groups of sampling sites considered together) into the third configuration (TC3). It should be noted that there has not yet been any study published which exploits the possible homogeneous characteristic of water quality monitoring sites to optimize the functioning of neural networks in estimating riverine dissolved oxygen. Three different setups (TC3-A, TC3-B, TC3-C) were examined, and for each, three sub-setups were assessed (TC3-A\#1, TC3-A\#2, etc., see Sect. 2.3).

The RMSE values for the setup TC3-A\#3 (min RMSE: $2.33 \mathrm{mgL}^{-1}$ ) were smaller than those for TC2-A (min RMSE $=4.25 \mathrm{mgL}^{-1}$ ), nevertheless these still exceeded reference values_(Table 2), despite expectations. An explanation of this occurrence may lie in the fact that sampling locations T03-T05, used in setup TC3-A, are highly affected by anthropogenic activities. Specifically, site T05 displays a significant difference from its two neighboring sampling locations (T03 and T04) upstream due to the dam and water barrage system at Tiszalök (Tanos et al., 2015; Fig. 1A). The average difference between sampling locations (TC3A) is approximately $0.23 \%$ (Table 4 ), which significantly exceeds the average differences indicated by CCDA between sampling locations in setups TC3-B and TC3-C $(0.11 \%$ and $0.09 \%$, respectively).

Taking all cases into consideration, the best results were obtained in setup C of the third configuration ('mixed structure'), with GRNN model providing the best estimation in the TC3-C\#2 sub-setup (RMSE $=0.73 \mathrm{mgL}^{-1}$ : an improvement of $\sim 61 \%$ over reference values $\left(1.88 \mathrm{mg} \mathrm{L}^{-1}\right)$.

It can be concluded that DO-estimation is more effective on the lower sections of the river, due to the smaller degree of variability in water quality parameters at the distinct sites (Table 1), or even between them (Table 4). This is attributed to the lower velocity and increased runoff of the river (Table 1; Hatvani et al., 2018; EC, 2015).

Compared to the studies found-in literature (Table A1), the configuration of the GRNN ANN model used on the River Tisza that incorporated the homogeneous characteristic of the sampling sites gave the second-best estimation for DO (RMSE $=0.73 \mathrm{mg} \mathrm{L}^{-1} ; \mathrm{R}^{2}=0.9$ ). Only an MLPNN model yielded a better estimation for DO, on the River Heihe (Wen et al., 2013). The other two configurations (TC1 and TC2) gave below-average estimates with respect to RMSE and R ${ }^{2}$, compared to those found in the literature (Table A1). It should be noted that although RMSE and $\mathrm{R}^{2}$ are objective metrics that allow the comparison of different 
model estimations, the models used to estimate riverine DO documented in Table A1 were applied under different circumstances regarding both the environmental setting and the input data. Nevertheless, the fact that the model accounting for the homogeneity of the sites performed best suggests that with a similar approach, improvements can be made in other cases as well (e.g. Table A1).

It should be noted that while DO was estimated with a reasonable degree of accuracy in the River Tisza with the training set size being limited to only approximately 300 observations, in the first and second setups this value was between 1300 and 1400. As is well known, the higher the number of observations

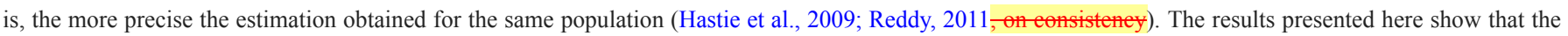
adverse effects of a lower sample size can be countered with a controlled and conscious selection of the training and test sets and spatial optimization. This does not contradict the statistical principle of statistical consistency, as the River Tisza in Hungary is not of a 'homogenous structure'.

\title{
5 Conclusions and outlook
}

The runoff, temperature, $\mathrm{pH}$ and electrical conductivity of 13 sampling locations were processed on the River Tisza using a linear regression and two ANN models (GRNN and RBFNN) to estimate the DO content of the river. The performance of the models was evaluated using RMSE and $\mathrm{R}^{2}$. An approx. 2:1 ratio was maintained in all cases between the training and test set sizes. Three configurations were considered. In the first configuration(TC1), the sampling locations were randomly allocated to the training or test set. This configuration was used as a reference model, as it provided an estimation covering the whole river section. In order to characterize different sections of the river in a way which would make them readily distinguishable, in the second configuration (TC2) a controlled selection of the sampling locations was employed to define the training and test sets based on their geographic locations, as these were proven to represent different water quality processes, a fact confirmed by CCDA. In the third configuration, the homogeneous characteristic of the different sampling sites was considered an additional factor when choosing the training and test sites.

By incorporating the homogeneous characteristic of the sites (TC3), a better overall performance was obtained, with a reduction of avg. 21\% in estimation error compared to estimations obtained from the reference configuration (TC1; regarding all three models), or even the second model (TC2), which did not incorporate spatial homogeneity. Regarding the best configuration (TC3), in the upper reach the linear regression and the ANNs were similarly incapable of explaining a high portion of variance (avg. $\mathrm{R}^{2}=0.31$ ), while in the middle- and lower reaches the average explained variance of the models was $81 \%$ and $87 \%$, and of these, the General Regression Neural Networks performed the best. They explained $85 \%$ and $90 \%$ of the variance of DO in the middle and lower reaches, respectively, even in the presence of a high degree of anthropogenic activity, as is the case at many locations on/over the whole course of (you cheose)the River Tisza.

It can be said that the increase in used data does not necessarily increase the goodness of the estimations. However, if the training set is chosen in a controlled way, e.g. by forming homogeneous groups of sampling sites and using their combined dataset, the performance of the estimation significantly increases. Thus, it is suggested that the methodology presented here be applied even in cases when an already acceptable estimation has been obtained for dissolved oxygen]

\section{Uncited reference}

\author{
Chen and Litu (2015).
}

\section{Acknowledgements}

We would like to thank Paul Thatcher for his work on our English version. The work of I.G. Hatvani was supported by the János Bolyai Research Scholarship of the Hungarian Academy of Sciences, the Hungarian Ministry of Human Capacities (NTP-NFTÖ-17). Thanks for the support of the Szent István University (FIEK_16-1-2016-0008; EFOP 3.4.3-16-2016-00012; 20430-3/2018/FEKUSTRAT), the MTA "Lendület" program (LP2012-27/2012). This is contribution No. XX $\underline{65}$ of 2ka Palæoclimate Research Group.

\section{Appendix A}

\section{Fig. A1}

Figure Replacement Requested
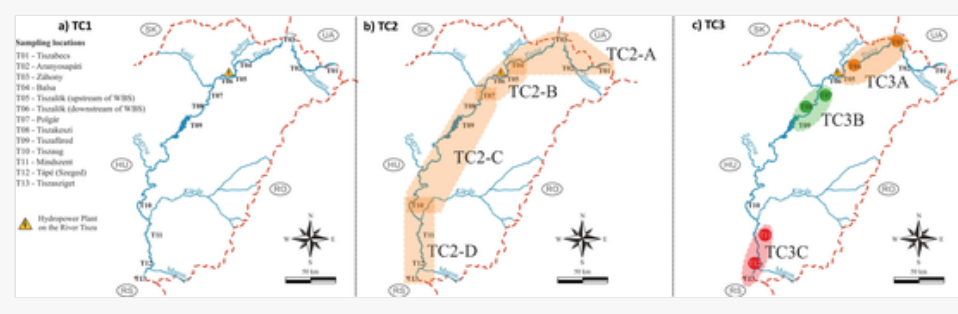

Illustration of the three different configurations: a) TC1 $\underline{\mathrm{A}}$,, $\mathrm{b}) \mathrm{TC} 2 \underline{\mathrm{B}}$ ) ande) $\mathrm{TC} 3 \underline{\mathrm{C}}$ ) used in the study. In TC 2 (B) the shaded backgrounds represent the sites used for training in the different setups, while in TC3 (C) these show the sites which were considered together for training and testing in the different setups. For details please see Section 2.3. Circles with similar colors in TC3 (C) show the homogeneous sampling sites determined in Tanos et al. (2015). 

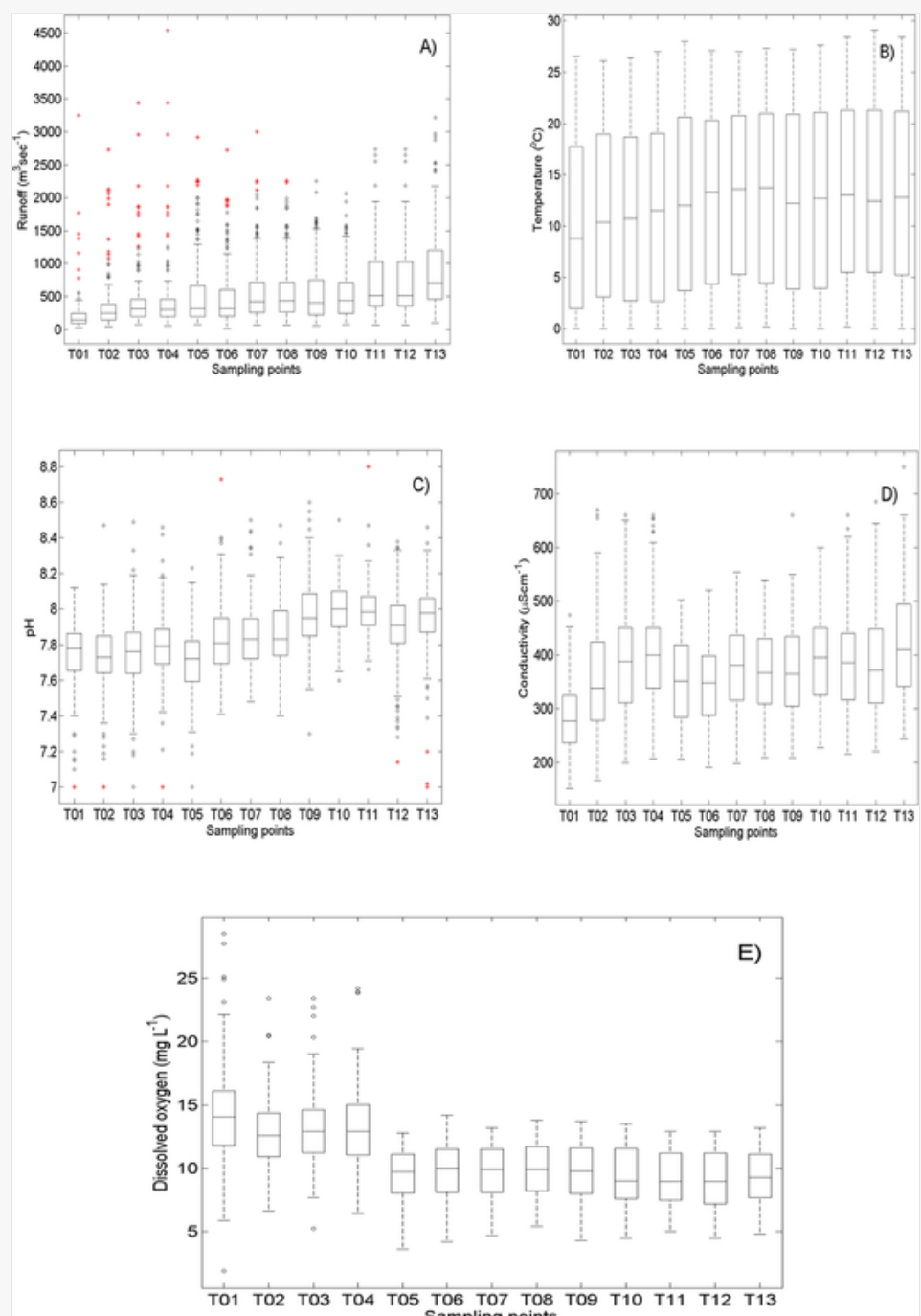


value of 1.5 times that of the interquartile range (outlying values) are indicated with a circle and those outside 3 times the interquartile range are marked with a redn asterisk (extreme values), the black lines in the boxes represent the median.

\section{Table A1}

(i) The presentation of Tables and the formatting of text in the online proof do not match the final output, though the data is the same. To preview the actual presentation view the Proof.

Results of dissolved oxygen estimation in literature and the present study. The selection column describes the way in which the training and test sets were divided, in which 'temporal' indicates an approach in which the ultimate time point(s) were used as the test set while 'Spatial' indicates the setup in which the test and training sets were chosen in a spatial manner using a combination of neighbouring sites. In the case of multiple models, the ones highlighted in bold performed the best. Abbreviations: ANFIS: Adaptive neuro-fuzzy inference system, GRNN: Generalized regression neural network, MLPNN: Multilayer perceptron; MLR: Multivariate linear regression, PLS2: Partial least squares regression, RBFNN: Radial basis function neural network, SVM: Support vector machine. The results from literature and the present study are both ordered in decreasing order of RMSE.

\begin{tabular}{|c|c|c|c|c|c|c|c|c|c|}
\hline Reference & River & $\begin{array}{l}\text { rkm } \underline{\text { River }} \\
\underline{\mathrm{km}}\end{array}$ & $\begin{array}{l}\text { Sample } \\
\text { points }\end{array}$ & $\begin{array}{l}\text { Number of years } \\
\text { assessed }\end{array}$ & Selection & Models & $\begin{array}{l}\text { Input } \\
\text { parameters }\end{array}$ & $\begin{array}{l}\text { Best RMSE }\left(\mathrm{mg} \mathrm{L}^{-1}\right) \\
\text { for the test set }\end{array}$ & $\begin{array}{l}\text { Best } R^{2} \text { for } \\
\text { the test set }\end{array}$ \\
\hline $\begin{array}{l}\text { Emamgholizadeh et } \\
\text { al., } 2014\end{array}$ & Karoon & - & 8 & 17 & random & ANFIS + MLPNN + RBFNN & 9 & 3.15 & 0.85 \\
\hline Singh et al., 2009 & Gomti & 500 & 8 & 10 & temporal & MLPNN & 13 & 1.23 & 0.76 \\
\hline Basant et al., 2010 & Gomti & 500 & 8 & 10 & random & MLPNN + PLS2 & 11 & 1.36 & 0.74 \\
\hline Bayram and Kankal, & Harsit & 143 & 9 & 1 & controlled & MLPNN + MLR & 2 & 0.94 & n.a. \\
\hline
\end{tabular}




\begin{tabular}{|c|c|c|c|c|c|c|c|c|c|}
\hline \multirow{2}{*}{$\begin{array}{l}2015 \\
\text { Ji et al., } 2017\end{array}$} & & & & & random & \\
\hline & $\begin{array}{l}\text { Wen-Rui } \\
\text { Tang }\end{array}$ & - & 8 & 5 & temporal & $\mathbf{S V M}+$ GRNN + MLPNN + MLR & 11 & 0.97 & 0.86 \\
\hline Ay and Kisi, 2012 & Arkansas & - & 2 & n. a. & spatial & MLPNN + RBFNN + MLR & 2 & 0.66 & 0.85 \\
\hline $\begin{array}{l}\text { Antanasijević et al., } \\
2014\end{array}$ & Danube & 588 & 17 & 9 & random & GRNN & 10 & 0.87 & 0.85 \\
\hline $\begin{array}{l}\text { Šiljić Tomić et al., } \\
2018 b\end{array}$ & Danube & 253 & 8 & 7 & temporal & MLPNN & 12 & 0.81 & 0.88 \\
\hline $\begin{array}{l}\text { Šiljić Tomić et al., } \\
2018 b\end{array}$ & Danube & 304 & 9 & 6 & temporal & MLPNN & 11 & 0.84 & 0.86 \\
\hline Wen et al., 2013 & Heihe & - & 3 & 6 & random & MLPNN & 8 & 0.46 & 0.94 \\
\hline $\begin{array}{l}\text { Present study, TC1 } \\
\text { conf.* }\end{array}$ & Tisza & 595 & 13 & 6 & random & RBFNN+ GRNN + MLR & 4 & 1.88 & 0.57 \\
\hline $\begin{array}{l}\text { Present study, TC2 } \\
\text { conf. }\end{array}$ & Tisza & 595 & 13 & 6 & spatial & RBFNN + GRNN + MLR & 4 & 1.53 & 0.71 \\
\hline $\begin{array}{l}\text { Present study, TC3 } \\
\text { conf. }\end{array}$ & Tisza & 54 & 3 & 6 & spatial & RBFNN + GRNN + MLR & 4 & 0.73 & 0.90 \\
\hline
\end{tabular}

Table Footnotes

* Reference model

\section{Table A2}

(i) The presentation of Tables and the formatting of text in the online proof do not match the final output, though the data is the same. To preview the actual presentation, view the Proof.

[Instruction: Please replace Table A2 with the attached table. Thank you!]Description of the used configurations, setups and sub-setups (for further information see Fig. A1/A-C inset maps).

\begin{tabular}{|c|c|c|c|c|}
\hline & & TC1 & TC2 & TC3 \\
\hline \multirow{2}{*}{ Configuration } & Used data set & total & total & $3-3$ selected stations \\
\hline & $\begin{array}{l}\text { Methods of selection of training and test } \\
\text { sets }\end{array}$ & random & $\begin{array}{l}\text { four neighboring stations in the test } \\
\text { set }\end{array}$ & $\begin{array}{l}\text { used data set: two homogeneous stations and next neighboring } \\
\text { station }\end{array}$ \\
\hline Setup & Application of methods & $\begin{array}{l}3 \text { seed values (see } \\
2.3)\end{array}$ & $\begin{array}{l}\text { Selection of four neighboring } \\
\text { stations }\end{array}$ & Selection of three stations \\
\hline \multirow[t]{3}{*}{ Sub-setup } & & none & none & Defining the training and test set \\
\hline & Number of cases & 3 & 4 & 9 \\
\hline & Notation & $\begin{array}{l}\text { TC1-A, TC1-B, TC1- } \\
\text { C }\end{array}$ & TC2-A, TC2-B, TC2-C, TC2-D & TC3-A\#1, TC3-A\#2, TC3-A\#3, etc. \\
\hline
\end{tabular}

\section{Appendix B Supplementary data}

Supplementary data to this article can be found online at https://doi.org/10.1016/j.ecoleng.2019.07.023.

\section{References}

(i) The corrections made in this section will be reviewed and approved by journal production editor.

Abonyi, A., Leitão, M., Lançon, A.M., Padisák, J., 2012. Phytoplankton functional groups as indicators of human impacts along the River Loire (France). Hydrobiologia 698, 233. doi:10.1007/s10750-012-1130-0.

Akkoyunlu, A., Altun, H., Cigizoglu, H.K., 2011. Depth-integrated estimation of dissolved oxygen in a lake. J. Environ. Eng. 137, $961-967$. 
Antanasijević, D., Pocajt, V., Povrenović, D., Perić-Grujić, A., Rictić, M., 2013. Modelling of dissolved oxygen content using artificial neural networks: Danube River, North Serbia, case study. Environ. Sci. Pollut. Res. 20, 9006-9013.

Antanasijević, D., Pocajt, V., Perić-Grujić, A., Rictić, M., 2014. Modelling of dissolved oxygen in the Danube River using artificial neural networks and Monte Carlo Simulation uncertainty analysis. J. Hydrol. 519, 1895-1907.

APHA, 1998. Standard Methods for the Examination of Water and Wastewater, 20th ed. American Public Health Association, Washington, DC.

Ay, M., Kisi, O., 2012. Modeling of dissolved oxygen concentration using different neural network techniques in Foundation Creek, El Paso County, Colorado. J. Environ. Eng. 138, 654-662.

Basant, N., Gupta, S., Malik, A., Singh, K.P., 2010. Linear and nonlinear modelling for simultaneous prediction of dissolved oxygen and biochemical oxygen demand of the surface water - a case study. Chemom. Intell. Lab. Syst. 104, 172-180.

Bayram, A., Kankal, M., 2015. Artificial neural network modeling of dissolved oxygen concentrations in a Turkish Watershed. Pol. J. Environ. Stud. 24, $1507-1515$.

Bayram, A., Uzlu, E., Kankal, M., Dede, T., 2015. Modeling stream dissolved oxygen concentration using teaching-learning based optimization algorithm. Environ. Earth Sci. 73, 6565-6576.

Ben-Gal, I., 2010. Outlier detection. In: Maimon, O., Rokach, L. (Eds.), Data Mining and Knowledge Discovery Handbook,, second ed.. Springer, US, Boston, MA, pp. 117-130.

Bevelhimer, M.S., Coutant, C.C., 2006. Assessment of dissolved oxygen mitigation at hydropower dams using an integrated hydrodynamic/water quality/fish growth model. Environ. Sci. Div. ORNL/TM2005/188.

Bolgovics, Á., Várbíró, G., Ács, É., Trábert, Z., Kiss, K.T., Pozderka, V., Görgényi, J., Boda, P., Lukács, B.-A., Nagy-László, Z., Abonyi, A., Borics, G., 2017. Phytoplankton of rhithral rivers: Its origin, diversity and possible use for quality-assessment. Ecol. Ind. 81, 587-596. doi:10.1016/j.ecolind.2017.04.052.

Butts, TA., Evans, RL., 1978. Effects of Channel Dams on Dissolved Oxygen Concentrations in Northeastern Illinois Streams. ISWS/CIR-132/78. [Instruction: Some references in the reference list (e.g. Butts and Evans, or EC2015, or Moreira and Poole 1993 etc.) are edited in a strange way in the pdf Proof. The authors are mentioned twice, although, here there is no indication of this error. Please do check. Thank you

]

Chapman, D.V., Bradley, C., Gettel, G.M., Hatvani, I.G., Hein, T., Kovács, J., Liska, I., Oliver, D.M., Tanos, P., Trásy, B., Várbíró, G., 2016. Developments in water quality monitoring and management in large river catchments using the Danube River as an example. Environ. Sci. Policy 64, 141-154. doi:10.1016/j.envsci.2016.06.015.

Chen, W.B., Liu, W.C., 2014. Artificial neural network modeling of dissolved oxygen in reservoir. Environ. Monit. Assess. 186, $1203-1217$.

Chen, W.B., Lit, W.C., 2015. In: Water Quality Modeling in Reservoirs using Multivariate Linear Regression and Two Neural Network Models, Hindawi Publishing Coran. doi:10.1155/2015/521721.

Connolly, N.M., Crossland, M.R., Pearson, R.G., 2004. Effect of low dissolved oxygen on survival, emergence, and drift of tropical stream macroinvertebrates. J. North Am. Benthol. Soc. 23 (2), 251-270.

Cox, B.A., 2003. A review of currently available in-stream water-quality models and their applicability for simulating dissolved oxygen in lowland rivers. Sci. Total Environ. 314-316, 335-377.

Csábrági, A., Molnár, S., Tanos, P., Kovác, J., 2015. Forecasting of dissolved oxygen in the river Danube using neural networks. Hungarian Agric. Eng. $27,38-41$.

Csábrági, A., Molnár, S., Tanos, P., Kovács, J., 2017. Application of artificial neural networks to the forecasting of dissolved oxygen content in the Hungarian section of the river Danube. Ecol. Eng. 100, 63-72.

Demuth, H., Beale, M., 2000. Neural Network Toolbox user's guide: MATLAB, The Mathworks Inc..

Dodds, W.K., 2002. Freshwater Ecology: Concepts and Environmental Applications, Academic Press, San Diego, California.

Dogan, E., Sengorur, B., Koklu, R., 2009. Modelling biochemical oxygen demand of the Melen River in Turkey using an artificial neural network technique. J. Environ. Manage. 90, 1229-1235.

Draper, N.R., Smith, H., 1981. Applied Regression Analysis, Wiley, New York.

EC (Eurepean Commision), 2015. River Basin Management Plans, 2012-2014 WFD public information and consultation documents for Hungary (http://e c.europa.eu/environment/water/participation/map_mc/countries/hungary_en.htm) Accessed on 2019.02.13. 
Emamgholizadeh, S., Kashi, H., Marofpoor, I., Zalaghi, E., 2014. Prediction of water quality parameters of Karoon River (Iran) by artificial intelligencebased models. Int. J. Environ. Sci. Technol. 11, 645-656.

ERPI, 2002. Maintaining and Monitoring Dissolved Oxygen at Hydroelectric Projects: Status Report. Technical Report 1005194, Palo Alto, California

Hastie, T., Tibshirani, R., Friedman, J., 2009. The Elements of Statistical Learning: Data Mining, Inference, and Prediction, second ed,. Springer.

Hatvani, I.G., Tanos, P., Várbíró, G., Miklós, A., Molnár, S., Garamhegyi, T., Kovács, J., 2018. Distribution of niche spaces over different homogeneous river sections at seasonal resolution. Ecol. Ind. 98, 804-811. doi:10.1016/j.ecolind.2018.11.059.

He, J., Chu, A., Ryan, M., Valeo, C., Zaitlin, B., 2011. Abiotic influences on dissolved oxygen in a riverine environment. Ecol. Eng. 37, $1804-1814$.

Heddam, S., 2014. Generalized regression neural network-based approach for modelling hourly dissolved oxygen concentration in the Upper Klamath River, Oregon. USA. Environ. Technol. 35, 1650-1657.

Ji, X., Shang, X., Dahlgren, R.A., Zhang, M., 2017. Prediction of dissolved oxygen concentration in hypoxic river systems using support vector machine: a case study of Wen-Rui Tang River, China. Environ. Sci. Pollut. Res. Int. 24 (19), 16062-16076.

Kanda, E.K., Kipkorir, E.C., Kosgei, J.R., 2016. Dissolved oxygen modelling using artificial neural network: a case of River Nzoia, Lake Victoria Basin, Kenya. J. Water Secur..

Kentel, E., Alp, E., 2013. Hydropower in Turkey: Economical, social and environmental aspects and legal challenges. Environ. Sci. Policy 31, $34-43$.

Kovács, J., Kovács, S., Magyar, N., Tanos, P., Hatvani, I.G., Anda, A., 2014. Classification into homogeneous groups using combined cluster and discriminant analysis. Environ. Modell. Software 57, 52-59. doi:10.1016/j.envsoft.2014.01.0100.

Kovács, J., Kovács, S., Hatvani, I.G., Magyar, N., Tanos, P., Korponai, J., Blaschke, A.P., 2015. Spatial optimization of monitoring networks on the examples of a river, a lake-wetland system and a sub-surface water system. Water Resour. Manage. 29 (14), 5275-5294. doi:10.1007/s11269-015-1117-5.

Kovács, J., Tanos, P., Várbíró, G., Anda, A., Molnár, S., Hatvani, I.G., 2017. The role of annual periodic behavior of water quality parameters in primary production - Chlorophyll-a estimation. Ecol. Ind. 78, 311-321. doi:10.1016/j.ecolind.2017.03.002.

Legates, D.R., McCabe, G.J., Jr., 1999. Evaluating the use of goodness-of-fit measures in hydrologic and hydroclimatic model validation. Water Resour. Res. 35, 233-241.

Maier, H.R., Dandy, G.C., 2000. Neural networks for the prediction and forecasting of water resources variables: a review of modelling issues and applications. Environ. Modell. Software 15, 101-124.

Moreira, J.R., Poole, A.D., 1993. Hydropower and its constraints. United States.

Mosteller, F., Tukey, J.W., 1977. Data analysis and regression: a second course in statistics. In: Addison-Wesley Series in Behavioral Science: Quantitative Methods, p. 588p.

Najah, A., El-Shafie, A., Karim, O.A., Jaafar, O., El-Shafie, A.H., 2011. An application of different artificial intelligences techniques for water quality prediction. Int. J. Phys. Sci. 6 (22), 5298-5308. doi:10.5897/IJPS11.1180.

Odum, H.T., 1956. Primary production in flowing waters. Limnol. Oceanogr. 1, 102-117.

Ouyang, H.T., 2018. Input optimization of ANFIS typhoon inundation forecast models using a Multi-Objective Genetic Algorithm. J. Hydro-environ. Res. 19, 16-27. doi:10.1016/j.jher.2018.01.002.

Palani, S., Liong, S., Tkalich, P., 2008. An ANN application for water quality forecasting. Mar. Pollut. Bull. 56, 1586-1597.

Prasad, R., Deo, R.C., Li, Y., Maraseni, T., 2017. Input selection and performance optimization of ANN-based streamflow forecasts in the drought-prone Murray Darling Basin region using IIS and MODWT algorithm. Atmos. Res. 197, 42-63. doi:10.1016/j.atmosres.2017.06.014.

R Core Team (2018) R: A Language and Environment for Statistical Computing. R Foundation for Statistical Computing, Vienna, Austria.

Reddy, T.A., 2011. Applied Data Analysis and Modeling for Energy Engineers and Scientists, Springer Science \& Business Media, New York.

Reynolds, C.S., 1984. Phytoplankton periodicity: the interactions of form, function and environmental variability. Freshw. Biol. 14, 111-142. doi:10.1111/j.1365-2427.1984.tb00027.x.

Ruane, R.J., Hauser, G.E., 1991. Factors Affecting Dissolved Oxygen in Hydropower Reservoirs, American Society of Civil Engineers, United States.

Schurr, J.M., Ruchti, J., 1977. Dynamics of $\mathrm{O}_{2}$ and $\mathrm{CO}_{2}$ exchange, photosynthesis, and respiration in rivers from time-delayed correlation with ideal sunlight. Limnol. Oceanogr. 22 (2), 208-225.

Shaikhina, T., Khovanova, N.A., 2017. Handling limited datasets with neural networks in medical applications: a small-data approach. Artif. Intell. Med. 75, 51-63. 
Šiljić Tomić, A., Antanasijević, D., Ristić, M., Perić-Grujić, A., Pocajt, V., 2016. Modeling the BOD of Danube River in Serbia using spatial, temporal, and input variables optimized artificial neural networks models. Environ. Monit. Assess. 188 (300), 1-12.

Šijić Tomić, A., Antanasijević, D., Ristić, M., Perić-Grujić, A., Pocajt, V., 2018. Application of experimental design for the optimization of artificial neural network-based water quality model: a case study of dissolved oxygen prediction. Environ. Sci. Pollut. Res. 25, 1-11. doi:10.1007/s11356-018$1246-5$.

Šiljić Tomić, A., Antanasijević, D., Ristić, M., Perić-Grujić, A., Pocajt, V., 2018. A linear and non-linear polynomial neural network modeling of dissolved oxygen content in surface water: Inter- and extrapolation performance with inputs' significance analysis. Sci. Total Environ. 610-611, 10381046.

Singh, K., Basant, A., Malik, A., Jain, G., 2009. Artificial neural network modeling of the river water quality - a case study. Ecol. Model. 220, 888-895.

Stanković, I., Várbíró, G., Gligora Udovič, M., Borics, G., Vlahović, T., 2012. Phytoplankton functional and morpho-functional approach in large floodplain rivers. Hydrobiologia 698, 217-231. doi:10.1007/s10750-012-1148-3.

Tanos, P., Kovács, J., Kovácsné Székely, I., Hatvani, I.G., 2011. Exploratory data analysis on the Upper-Tisza section using single and multi-variate data analysis methods. Central Euro. Geol. 54 (4), 345-356.

Tanos, P., Kovács, J., Kovács, S., Anda, A., Hatvani, I.G., 2015. Optimization of the monitoring network on the River Tisza (Central Europe, Hungary) using combined cluster and discriminant analysis, taking seasonality into account. Environ. Monit. Assess. 187 (9), 575. doi:10.1007/s10661-015-4777-y.

Tanos, P., 2017. Application of multivariate- and time series analysis methods on the water quality data sets of the water system of the river Tisza. Ph.D. dissertation, 115p. https://doi.org/10.18136/PE.2017.657.

Thompson, D.H., 1925. Some observations on the oxygen requirements of fishes in the Illinois River. Illinois Natural History Survey Bulletin. 15 , No. 7. http://hdl.handle.net/2142/45974.

Várbíró, G., Ács, É., Borics, G., Érces, K., Fehér, G., Grigorszky, I., Nagy-László, Z., 2007. Use of Self-Organizing Maps (SOM) for characterization of riverine phytoplankton associations in Hungary. Large Rivers 383-394.

Verma, A.K., Singh, T.N., 2013. Prediction of water quality from simple field parameters. Environ. Earth Sci. 69, 821-829.

Wang, H., Hondzo, M., Xu, C., Poole, V., Spacie, A., 2003. Dissolved oxygen dynamics of streams draining an urbanized and an agricultural catchment. Ecol. Model. 160, 145-161.

Wang, Q., Li, S., Jia, P.Q.C., Ding, F., 2013. A review of surface water quality models. Sci. World J.. doi:10.1155/2013/231768.

Wen, X., Fang, J., Diao, M., Zhang, C., 2013. Artificial neural network modelling of dissolved oxygen in the Heihe River, Northwestern China. Environ. Monit. Assess. 185, 4361-4371.

\section{Highlights}

- Forecasting dissolved oxygen in a river using artificial neural networks (ANN).

- Multivariate Linear Regression, Radial Basis Function \& General Regression NN compared.

- Spatial variability of water quality incorporated into the models.

- Best performing model was the spatially optimized General Regression Neural Network.

- General applicability of the methodology for other river systems presented.

\section{Appendix B Supplementary data}

The following are the Supplementary data to this article:

Multimedia Component 1

Supplementary data 1 


\section{Queries and Answers}

Query: Your article is registered as a regular item and is being processed for inclusion in a regular issue of the journal. If this is NOT correct and your article belongs to a Special Issue/Collection please contact p.sivakumar@elsevier.com immediately prior to returning your corrections.

Answer: No, it does not belong to any special issue.

Query: Please confirm that the provided email hatvaniiig@gmail.com is the correct address for official communication, else provide an alternate e-mail address to replace the existing one, because private e-mail addresses should not be used in articles as the address for communication.

Answer: Yes, it is the correct one.

Query: The author names have been tagged as given names and surnames (surnames are highlighted in teal color). Please confirm if they have been identified correctly.

Answer: Yes

Query: Note that, Fig. 3 has been changed to Fig. A1. Please check and correct if necessary.

Answer: Yes, it is correct. Fig 3 should be Fig. A1.

Query: Uncited references: This section comprises references that occur in the reference list but not in the body of the text. Please cite each reference in the text or, alternatively, delete it. Any reference not dealt with will be retained in this section.

Answer: Please delete the reference. 